\title{
İş bölümünün, Sosyal Politika ve Toplumsal Dayanışma Açısından Sosyolojik Çözümlemesi
}

\author{
Sociological Analysis of the Division of Labor in terms of Social Policy and Social \\ Solidarity
}

Dr. Aziz ŞEKER ${ }^{D} 1$

\begin{abstract}
$\ddot{O} z$
Sosyal teoride iş bölümü olgusu, Durkheim sosyolojisinin önemli anahtar kavramlarından biridir. Durkheim'e göre modern toplum organik dayanışmanın arttığı, iş bölümüne ve meslekleşmeye dayalı bir toplum modelidir. Küreselleşme süreciyle birlikte yeni kavramsallaştırmalarla tanımlanmaya çalışılan modern sonrası toplumlarda da iş bölümünün önemini ve mesleklerin toplumsal etkileşimdeki işlevlerini korumaya devam ettiğini gözlemlemekteyiz. Durkheim'in temel varsayımına göre, iş bölümünün yaygınlığı bir toplumun gelişmişlik göstergeleri arasında yer alır. Ayrıca iş bölümü toplumsal bütünleşme açısından da önemli bir yöne sahiptir. Bu anlamda toplumsal dayanışmaya ve bütünleşmeye katkı veren iş bölümünün, sosyal politikanın gelişimine ve toplumsal korumaya olumlu yansıdığını söyleyebiliriz. Bu çalışma, Durkheim'in iş bölümüne atfettiği özelliklerden yola çıkarak; sosyal politika ile sosyal dayanışma açısından iş bölümünün sosyolojik işlevi ve önemini irdelemek amacıyla yapılmıştır. Ayrıca çalışmanın iş bölümü ve sosyal politika arasındaki ilişkiyi ortaya koymak açısından yol gösterici olacağı düşünülmektedir.
\end{abstract}

Anahtar Kelimeler: Emile Durkheim, iş bölümü, sosyal politika, toplumsal dayanışma

Makale Türü: Derleme

\begin{abstract}
The phenomenon of division of labour in social theory is one of the important key concepts of Durkheim's sociology. According to Durkheim, modern society is a society model based on division of labour and professionalization, where organic solidarity increases. In the post-modern societies that are tried to be defined by the new conceptualizations with the globalization process, we observe the importance of the division of labour and the functions of the professions in social interaction are maintained. Durkheim's basic assumption suggests that the prevalence of division of labour is one of the indicators of development of a society. In addition, the division of labour has a major importance in terms of social integration. In this respect, it is possible to argue that the division of labour, which contributes to social solidarity and integration, has a positive impact on the development of social policy and social protection. Based on the characteristics Durkheim attributed to division of labour, this study aims to elaborate the sociological function and importance of the division of labour in terms of social policy and social solidarity. Furthermore, the study is thought to be enlightening in terms of revealing the relationship between division of labour and social policy.
\end{abstract}

Keywords: Emile Durkheim, division of labour, social policy, social solidarity

Paper Type: Review

\footnotetext{
${ }^{1}$ Amasya Üniversitesi, shuaziz@gmail.com

Atıf için (to cite): Şeker, A. (2020). İş bölümünün, sosyal politika ve toplumsal dayanışma açısından sosyolojik çözümlemesi. Afyon Kocatepe Üniversitesi Sosyal Bilimler Dergisi, 22(1), 20-27.
} 


\section{Giriş}

Toplumsal yapıyla ilgili analizlerde evrenselliği bulmaya ve evrensellik üzerinden bir toplumbilim inşa etmeye çalışan Durkheim'in, ulus devlet olmaya çalışan bütün kültürel-siyasaldini birlikteliklere, ideolojik bir umut olduğu en azından bir olanaklar alanı açmaya çalıştığ bilinmektedir. Bu özelliğiyle Durkheim, sosyolojinin de kurucuları arasında kabul edilmektedir. Durkheim'in modern toplumların yapısını anlamaya dönük; iş bölümü, toplumsal dayanışma biçimleri, toplumsal uyum, toplumsal bütünleşmenin toplum açısından önemi, toplumsal düzen gibi kavramları ele alınarak; bunların sağlıklı bir toplum ya da iyi bir toplum olmaya katkıları üzerine yapılan tartışmalar, Durkheim sosyolojisinin güncelliğini koruduğunu göstermektedir. Durkheim sosyolojisi, toplumsal yapı söz konusu olduğunda iş bölümü, dayanışma tipleri ve sosyal düzen kavramları ile daha çok ön plana çıkmaktadır. Pozitivist yaklaşımı, bilimsel argümanlarının dayanakları arasında gören Durkheim, toplumsal gerçeği ele alırken, bu bilimsel yöntemin olanaklarıyla toplumu ve bireyi anlamaya ve anlatmaya çalışmıştır. Bilimsel yöntemi gereğince, Durkheim için toplum bir tür organizmadır ve bu organizmanın her parçası, kendine özgü bir işlevi yerine getirir. Toplum kendi için kendiliğinden var olan, bireylerin boyun eğdiği, kendine özgü yasalara sahip olan işlevsel bir bütündür. Toplumsal organizma, yapısını ve görevini kendiliğinden değiştiren ve yeni uyumlar arayan bir iç dinamiğe sahiptir. Ancak, karşılıklı ve uyumlu bir bağımlılığa gereksinmesi olduğu için söz konusu değişim, sistematik bir bütün içinde sınırlandırılmıştır (Durkheim, 1985, s. 10). Toplumsal organizmanın sağlıklı işleyişi ise toplumun organik dayanışmaya doğru evrilmesinde anlam ve bütünlük kazanır.

Durkheim'in eserlerinde iki ana tema bulunmaktadır: Birincisi, toplumsal olanın bireysel olan üzerindeki önceliğidir ve ikincisi, toplumun, bilimsel olarak incelenebileceği fikridir. Bu temalardan ikisi tartışılmaya devam ettiği için Durkheim bugün hâlâ ilgi uyandırıcıdır (Ritzer ve Stepnisky, 2014, s. 76). Durkheim özellikle toplumsal bütünlüğün önemi ve onun bireysel bilinç üzerindeki belirleyiciliğini vurgulama eğilimindeyken, sosyal gerçeklik, işlev, nedensellik, genellik gibi sui generis kavramlar üzerinde çalışmalar yapmıştır. Toplum çözümlemelerinde, pre-modern toplumlardaki mekanik dayanışmanın yanı sıra modern toplumlardaki organik dayanışmanın toplumlar için işlevi üzerindeki çalışmaları ve görüşleri geniş bir literatür oluşturmaktadır. Ona göre sosyoloji, iyi bir toplumun yeniden inşasına dair tartışmalarda ve sosyal sorunların çözüm yollarıyla ilgili konularda bilim kimliğiyle bizlere yardımcı olabilir (Mazman, 2008, s. 67-83). Durkheim'in bu anlamda altını çizdiği nokta, "toplum-topluluk gerçekliğinin" önemidir. Toplum ve bilimsel bakış açısı arasında anlamlı bir ilişki bulunmaktadır. $\mathrm{Bu}$ bağlamda bir bilimin gelişmesi, ele aldığı sorunları çözme yönünde gösterdiği ilerlemeyle belli olur. Toplumbilimsel yöntem de toplumsal olguların nesneler gibi, yani bireyin dışındaki gerçeklikler gibi incelenmesi gerektiği temel ilkesi üzerine oturur. Çünkü toplumlar olmadan toplumbilim olamaz; yalnızca bireylerin bulunması halinde toplum olamaz (Durkheim, 1992, s. 15-18).

Durkheim'in iş bölümü kavramı, toplumsal yapıyı etkileyen olguların toplumsal yönleriyle ele alınması gerektiği yönündeki tezleri, iyi işleyen ya da sosyal sorunlarını çözebilen, refah içindeki toplum düşüncesine bizleri götürür. Bu anlamda sosyal politikanın, 21. yüzyılda toplumları iyileştirici yönüne baktığımızda, Durkheim'in bu çözümlemeye sunduğu teorik zenginlik göz ardı edilmemelidir. Öyle ki sosyal politikanın amacı, son kertede toplumun esenliğini sağlamaktır. Durkheim'i desteklercesine, iş bölümüne dayalı organik dayanışma toplumlarının gelmiş olduğu nihai aşamadır. Bu niteliğiyle, özünde her toplumsal kurum gibi sosyal politika bile bir evrim içinde oluşmuştur. Yoksullara, yaşlı bireylere ve çocuk gibi güçsüzlere, engellilere ve toplumsal koruma gereksinimi içine düşmüş diğer insanlara yardımlardan başlayarak, kişisel ve toplumsal dayanışmalara kadar uzanmış ve kapitalist çağın doğuşuyla birlikte sosyal sınıfların ilişkilerine ve devletin yeni görevler yüklenmesine dönük boyutlara kadar gelmiştir (Talas, 1990, s. 5). Bu yolda toplumun uzmanlaşmış olması, insan gücünün toplumsal katılımı ve çalışma yaşamında meslekleşmesi ise, toplumsal yarar ve düzen açısından her şeyin ötesinde sağlıklı bir planlamanın yapılmasıyla mümkün olmuştur. $\mathrm{Bu}$ 
değerlerle gelişen toplumlarda toplumsal özyapının işlevi, belli bir toplum içindeki insansal gücü bu toplumun sürekli işlemesi amacı için biçimlendirip yönlendirmektir ki, bireyin varlık sorunu da ancak bu yolla aşılabilir. Çünkü toplumsal esenliğe katkı veren birey, toplumsal organizma içinde üstlendiği rol ölçüsünde fail olabilmektedir (Durkheim, 1985, s. 14; Fromm, 1989, s. 96).

\section{Toplumsal İşbölümü ve Sosyal Politika}

İşbölümünün ortaya çıkışı, insanlık tarihinde uzun dönemleri kapsamaktadır. Mevcut anlamına ve rolüne ulaşması bir birikimin ürünüdür. Toplumsal uyuma katkısı ve toplumsal faydası düşünüldüğünde, iş bölümü, yalnızca ekonomi dünyasına özgü değildir. Onun artan etkisi toplumun en değişik alanlarında görülebilmektedir. Siyasal, yönetsel ve yargısal işlevler gittikçe daha çok uzmanlaşmaktadır. Sanatsal ve bilimsel alanlarda dahi durum böyledir. İşbölümü hakkında varılacak yargı ne olursa olsun, onun toplumsal düzenin en önemli temellerinden biri olduğu ve giderek daha çok o duruma geldiği herkes tarafindan çok iyi anlaşılmaktadır. İşbölümünün her gün daha büyük ölçülerdeki gelişmesinin sonucunda, toplumsal dayanışma biçim değiştirmektedir. Dolayısıyla iş bölümünü nesnel biçimde değerlendirmenin tek ölçütü, onu önce kendi başına ve tümden kuramsal olarak incelemek, ne işe yaradığını ve neye dayalı olduğunu araştırmak, kısacası onun hakkında olabildiğince tam bir görüş sahibi olmaktır. İşbölümünün gelişmesinde toplumsal-ekonomik koşulların ağırlıklı bir payı bulunmaktadır. İşlevsellik açısından bakıldığında iş bölümünün, toplumsal yapının gelişimine bağlı olarak insanlar için gerçek gereksinimlerin belirlediği bir yönde yetkinleştiği görülmektedir. Durkheim'e göre iş bölümü olgusu, çalışanların üretim güç ve becerisini artırırken; toplumların düşünsel ve maddi gelişmesinin zorunlu gereği ve uygarlığın kaynağı olarak kabul edilmektedir (Durkheim, 2014, s. 61-64-69-76). Bu özelliğiyle çalışma yaşamı üzerindeki ahlâki etkisinden söz edilebilir. Çalışma yaşamını ve dezavantajlı gruplara yönelik yapılacakları düzenleyen sosyal mevzuat ve sosyal politika ilişkisi bakımından, iş bölümünün birtakım toplumsal kuralların oluşumuna ve toplumsal işlevin sürdürülmesine yansıması göz ardı edilemez.

Toplumsal yapıda iş bölümünün giderek gelişmesiyle, mekanik dayanışma yerini başka türde bir dayanışmaya bırakır: organik dayanışmaya. Bireyler farklı görevler üstlenmeleri sebebiyle farklılaşırlar; buna bağlı olarak, bireysel irade bağımsızlaşıp, gelişirken, toplu irade de o ölçüde, etkinliğini kaybeder. Bu toplumda, farklı görevlerin karşılıklı organik ilişkisi, bireyi topluma, toplumu da bireye giderek daha fazla bağlar. İşbölümü, böylece, toplu iradenin yerini almış, çağdaş toplum bütünlüğünü sağlayıcı bir rol üstlenmiştir. İş bölümünün çağdaş toplumlarda ulaştığını bildiğimiz ileri düzeye bakarak, toplumsal yapıyı bütünleştirip birliğini sağlayacağını düşünebiliriz (Durkheim, 1985, s. 12; 2014, s. 89). İşbölümünün sosyal politikanın amacına uygun tarzda toplum bütünlüğüne katkısı burada sosyolojik bir değer kazanmaktadır. Elbette meslek örgütlerinin rolleri gereği, organik dayanışma açısından toplumsal bütünleşmeye maddi ve manevi etkileri söz konusudur. Kısaca bu içerikteki bir dayanışmanın gelmiş olduğu aşama, toplumsal kurumlara; din, ekonomi, aile, hukuk, sosyal refah vb. başta olmak üzere özelde toplumsal koruma uygulamalarına yani sosyal politika pratiklerine olumlu anlamda yansımaktadir.

\section{Meslek Örgütleri ve Organik Dayanışma}

İşbölümünün ilerlemesine bağlı olarak meslek kümelerinin çağdaş halkların toplumsal örgütlenişi ile siyasal örgütlenişe yansımalarını Durkheim, ahlâki etkilerinden yola çıkarak şöyle değerlendirmektedir:

"Biz meslek grubunda her şeyden önce bireylerin bencilliklerini sınırlayabilecek, çalışanların yüreklerine daha güçlü bir topluluk dayanışması duygusu koyabilecek, sanayi ve ticaret ilişkilerinde güçlünün haklılığı yasasının bunca kaba biçimde uygulanmasını engelleyebilecek ahlâki bir etki gücü görüyoruz. Meslek dernekleri, tarihin pek büyük bölümünde, ahlâk çöküntüsüne yol açmak şöyle dursun, ahlâki bir rol yerine getirmişlerdir. Mesleki örgütün siyasal örgütlenişimizin temeli ya da 
temellerinden biri olmaya aday olduğunu bile düşünebiliriz" (Durkheim, 2014, s. 2131-49).

Toplumlar ilerledikçe, meslek örgütlerinin yapısı değişmektedir. Örneğin sanayileşmenin büyük toplum kesimlerine kapsamlı yansımalarıyla birlikte ortaya çıkan sosyal devlet arayışları, 20. yüzyılda farklı bölgelerde benzer hizmetler veren loncaların işlevlerini yitirip yerini daha büyük meslek örgütlenmelerine bırakmasının gerekçelerini beraberinde getirmiştir. Meslek örgütlerinin toplumsal yapının temel ögelerinden biri olduğunu hatta "kalıcı bir kurum" olduğunu savunan Durkheim için, gözetilmesi gereken düşünce "toplumsal yapının genel sağlığına" yüklediği önemde anlam bulmaktadır. Buradan hareket edildiğinde, toplumun sağlıği/toplumun esenliği doğrultusunda, ekonomik ve sosyal koşullara bağlı sorunların çözümünde meslek örgütlerinin yapıcı rol alabilecekleri ifade edilebilir.

\section{Sosyal Politika ve Toplumsal Bütünleșme}

Sosyal politika, bugünkü geniş anlamıyla, bir ülkede çeşitli toplumsal sorunların çözümü ya da yol açtığı zararların en aza indirilmesine ilişkin uygulanan politika ve önlemler bütünü olarak belirtilmektedir (Koray ve Topçuoğlu, 1995, s. 1). Sosyal politika yer yer ideolojik bir argüman gibi ileri sürülse bile ortaya çıkış koşulları ve genel amacıyla toplumsal bir olgudur. Çünkü toplumun büyük çoğunluğunu kapsayıcı iyileştirici hizmetlerden oluşmaktadır. Bu özelliğiyle, çalışma yaşamı başta olmak üzere toplumsal yaşamı düzenleyici yönlere sahip olduğu düşüncesi, yasa yapıcıların ve uygulayıcıların dikkatinden kaçmamıştır. Bunun yanında toplumsal koruma ve sosyal hizmet ihtiyacı bulunan yaşlılar, engelliler, yoksullar gibi çok sayıda sosyal refah alanı da sosyal politikanın odaklandığı konular arasında yer almaktadır.

Günümüzde küresel risklerin ve sosyal sorunların yoğunlaştığı koşullarda, küresel sosyal politikalar oluşturmak adına Durkheim, toplumsal düzenin sürekliliği gözetildiğinde, referans alınması gereken bir yerde durmaya devam etmektedir. Bu minvalde sosyolojinin bir uygulama alanı kabul edilen sosyal politika olgusunun, çalı̧̧ma sosyolojisiyle etkileşimi Durkheim'in toplumsal olguları ele alış yöntemiyle değerlendirilebilir. Aynı zamanda bir sosyal reformist kabul edilen Durkheim'de bir toplumsal olgu, herhangi bir toplumsal çıkarı belli bir genellikle biraz karş1liyorsa, toplum içinde meydana gelen hemen hemen bütün fenomenler için bu niteleme kullanılır. Bireysel olgulardan çok farklı sui generis bir gerçeklik oluştururlar. Belirli bir yaptırıma dayanırlar. Bu olgular sosyolojinin gerçek alanını oluştururlar. Yoksulluk, intihar, göç, aile, engellilik, suç, işsizlik, toplumsal cinsiyet eşitsizliği, çocuk refahı, şiddet, yaşlılık gibi olguları bu açıdan ele almak mümkündür. Sosyal politika işte bu ve buna benzer toplumsal olgular alanında düzenleyicidir. Sosyal teori bilimsel yöntem ışığında bu olguların tanımını, nedenlerini, sonuçlarını, kavramsallaştırmasını, sınıflandırılmasını ve çözümlenmesini yapar. Durkheim'e göre toplumbilimci/sosyolog, ne zaman, herhangi bir toplumsal olgular sınıfinı araştırmaya girişirse, onları bireysel tezahürlerinden ayrılmış olarak ortaya çıktıkları bir yandan incelemeye çalışmalıdır. Nesnel olmalıdır (Durkheim, 1985, s. 74). Onun ifade edişiyle, "olağandışı olan, sayrıl (patolojik) olgular"ın ele alınması sosyolojik açıdan zorunludur. Organik dayanışmalı toplumlarda sosyal politika belirginken daha gerilere gidildiğinde toplumların gelişmişlik aşamalarına göre dayanışmadan ne anlaşıldığ 1 değişmektedir. Bu nedenle dayanışma konusu sosyolojinin inceleme alanına girmektedir. $\mathrm{Bu}$, ancak toplumsal etkileri aracılığıyla iyi anlaşılabilecek bir olgudur (Durkheim, 2014, s. 94). Örneğin mekanik dayanışmanın toplumsal yapıya etkilerine bakıldığında, suç, hukuk, sosyal yardımlaşma, ailenin işlevleri, toplumsal organizasyon gibi temel yaşamı içeren süreçlerin nasıl bir yön aldığı ortaya çıkar. Mekanik dayanışmanın somutluk bulduğu toplumlarda yani uygarlıkça aşağı durumdaki toplumlarda hukuk, yalnızca ceza hukukundan oluşuyorsa, dinsel hukuk her zaman bastırıcı nitelikteyse, daha doğrusu toplumsal dayanışmanın-ortak bilincin kurgulanışı bu yöndeyse, bu orjinli toplumlarda sosyal dayanışmanın, sosyal sorunlara bakış açısı sosyal hukuk gelişmediği için toplum liderleri gibi güçler ve komşuluk ilişkilerince belirlenen özelliktedir. Dinin başat olduğu bu toplumlarda, sosyal sorunlara bakış açısında hayırseverlik temelli bir anlayış vardır. İnsana yardım mesleklerinin henüz ortaya çıkmadığı koşullarda, yoksul insanların sorunlarının çözümünde 
flantropik güdülerin yönlendirdiği hayırseverlik davranışı egemenken, sosyal yardımın dağıtımını bu dönemlerde en yaygın haliyle din ve toplum liderleri yapmıştır. Bu tür bir sosyal yardım dağıtım biçimi, Weber'in kavramsallaştırmasıyla, sanayileşmeyle rasyonelleşen ve bürokratikleşen devlet yapısıyla yerini daha gelişmiş mekanizmalara bırakmıştır. Aynı zamanda bu dönem, endüstri kapitalizminin dünya ekonomisinin, temsil ettiği toplumsal düzenin, onu meşrulaştırır ve onaylar görünen fikirlerin ve inançların (akıl, bilim, ilerleme ve liberalizm) gösterdiği muazzam ilerlemeleri niteler (Durkheim, 2014, s. 108; Hobsbawm, 2012, s. 15; Şeker, 2015, s. 11).

Konuyla ilgili şöyle bir çıkarsama yapmak mümkündür: Tarihin kuşku götürmez biçimde saptadığı bir gerçek varsa, o da dininin toplumsal yaşamın gittikçe daha küçük bir alanını kapsamakta olmasıdır. Başlangıçta her yere uzanıyordu; toplumsal olan her şey dinseldi, bu iki sözcük aynı anlama geliyordu. Sonra azar azar siyasal, ekonomik, bilimsel işlevler dinsel işlevden özgürleşip kendi başlarına oluşmaya koyuluyor ve gittikçe daha belirginleşen bir dünyasal özellik kazanıyorlardı. Sonuçta iş bölümünün, toplumsal dayanışmanın önde gelen kaynağı olduğundan, aynı zamanda ahlâk düzeninin temeli olması aslında sosyal politikanın ortaya çıkış koşullarını beraberinde getiriyordu (Durkheim, 2014, s. 207-456). Toplumsal değişme ve ilerlemeye kaynaklık eden faktörlerden birisi olarak gün yüzüne çıkan iş bölümü, toplumu rasyonelleştirmenin yanı sıra işlevsel kılmakta, uzmanlaştırmakta daha ötesinde ortaya çıkış koşullarını beslediği sosyal politikanın kurgulanacağı bir çalışma alanını beraberinde getirmektedir. Bu yolda toplumsal yarara hizmet eden bir ahlâk anlayışı eğer sosyal adaletle kimlikleşiyor ise birey-toplum bütünleşmesine katkısı göz ardı edilemez.

Genel bir değerlendirmede bulunmak gerekirse, Durkheim'e göre iş bölümü tamamıyla modern bir olgu değildir; fakat geleneksel toplumlarda daha ilkeldir ve genellikle cinsel iş bölümüyle sınırlıdır. İşbölümünde uzmanlaşma modern sanayi üretiminin sonucudur. İşbölümündeki farklılaşmanın, kolektif bilincin/vicdanın yaygınlığında azalmaya yol açması, sosyal politikanın bir gereksinim olarak ortaya çıkış dinamiklerini beslemiştir. Çünkü organik toplum, insanın haklarını ve değerini vurgulayan ahlâki idealler ortaya çıkarmıştır. Meslek gruplarının varlığ 1 ise bu süreci pekiştirmiştir (Giddens, 2014, s. 131-139). Dolayısıyla iş bölümünden doğan organik dayanışmanın hâkim olduğu toplumlarda, iş bölümü ilerledikçe meslek tiplerinin sayısı artmış, yazılı hukuk toplumlar açısından onarıcı hâl almış ve toplumsal değişme bağlamında olumlu yönde bir gelişme olmuştur. Toplumsal sözleşme ve ortak bilincin, Roma'nın On İki Levha Yasası'ndan günümüze kadar, toplumlardaki yeri de değişmiştir. Hukuk seküler nitelik kazanıp ve din toplumsal yaşam üzerindeki temel belirleyiciliğini yitirdikçe, yalnızca ibadethanelere çekildikçe organik dayanışmanın toplum üzerindeki etkisine daha net tanıklık edilmiştir. Toplumsal ilerlemenin gelmiş olduğu düzey, kendi dinamiğinde toplumsal dayanışmanın organik bir özellik kazandığı gerçeğidir. Açıkçası yeni toplum tipinin, organlarıyla birlikte bu duruma uygunluk göstermesidir. Durkheim'in öngörüsüyle başlangıçta, dayanışmanın hemen hemen tek biçimi görülen mekanik dayanışmanın giderek alanını yitirmesi ve organik dayanışmanın yavaş yavaş üstün duruma gelmesi tarihin bir yasasıdır (Durkheim, 2014, s. 172213). Bu tarihi yasaya göre, toplumsal organizmanın gereksinimleriyle bir toplumsal olgu arasındaki ilişki, o toplumsal olgunun işlevini belirler. Toplumsal bir olgunun nedeni bir başka toplumsal olgudur ve bu sonuncunun işlevi de zorunlu olarak, toplumsal bir işlevdir, çünkü toplumsal açıdan yararlıdır. Sosyolog organik dayanışmayı yeniden kurabilmek amacıyla işe karışmalıdır, patolojik-sayrıl olanı yok etmenin çarelerini göstermelidir. Devletin görevi organik dayanışmayı sağlamaktır. Devlet, demokratik organizasyonun vazgeçilmez unsurudur. Devletin görevi yığınların bilinçsiz isteklerini yerine getirmek değil, kesinlikle bu isteklerden bağımsız olan toplumsal gerçekliğin gereksinimleri doğrultusunda, doğru, ussal, özgün hedefler göstermektir. Devlet, ekonomik yaşamı denetleyip, düzenliyorsa, zorunlu olarak toplumcudur (Durkheim, 1985, s. 11-13-17-18-21).

Bu noktada devletin toplumsal çabası, bütün toplumsal kesimleri ele aldığında tek tek bireyleri aşar ve nedensellik ilişkileri kapsamında bir dinamiğe sahip her bir toplumsal olguyu 
genel hatlarıyla görür. Toplum belirleyicidir, devlet ise belirleyici olan toplumun sağliklı işleyişinde, organik dayanışmanın-iş bölümünün önemini kavradığı için toplumun refahına değer katacak düzenlemelere doğrudan ya da dolaylı müdahalelere kapı aralayabilir. Sosyal politikanın önemi burada bütünlük ve netlik kazanmaktadır. Organik dayanışmanın başat olduğu uzmanlaşmış toplum tiplerinde biliyoruz ki, mekanik dayanışma toplumlarına göre sosyal refah alanları özellikle sosyal mevzuatın ilgi alanına giren çalışma yaşamı, göç, suçluluk, kentleşme, aile hukuku, insan hakları, halk eğitimi, sağlık, çocuk, kadın, engellilik, sosyal yardım, yaşlılık, halk sağlığı vb. toplumun geniş kesimlerini ilgilendiren konularda devletin toplum adına düzenleyici rolü ya da yükümlülükleri belirginleştirilmiştir. Toplumsal gereksinimler ölçüsünde kamu hukuku işlevsel olmuştur. Böylece toplum kendi yönünden, üyelerini artık üzerinde haklara sahip olduğu nesneler halinde değil, kendisiyle vazgeçemeyeceği bir biçimde işbirliği yapan ve kendilerine karşı ödevlerle yükümlü olduğu varlıklar gibi görmeyi öğrenir (Durkheim, 2014, s. 269).

Günümüzde gelinen süreç toplumların iş bölümüne dayalı organik dayanışmalı toplumlara doğru değiştiği, bunun en olumlu getirisinin ise insana ve topluma bakışta, sosyal sorunları çözüşte sosyal politika odaklı evrensel bir yaklaşımın benimsenmiş olduğudur. $\mathrm{Bu}$ yaklaşımın felsefi özünde, insani ilişkiler öteki kişinin refahı ve iyiliği için duyulan bir sorumluluk temelinde yürütüldügü oranda ahlâkiliğini korurken (Bauman, 2015a, s. 81), insanın değerli ve onurlu bir varlık olduğu tezi, yalnızca insan hakları aktivistlerinin savunduğu bir düşünce olmamış, toplumsal bütünleşme adına dünyanın büyük bir çoğunluğunun üzerinde uzlaşı sağladığı bir çalışma alanı ortaya çıkarmıştır.

\section{Sonuç ve Öneriler}

İnsan, tarihsel değişme ve sosyal gelişme süreçleri açısından bakıldığında, tarih içinde çok büyük şeyler pahasına daha karmaşı, daha üretken toplum biçimlerine yükselmiştir. Şüphesiz ki, bunun bir bedeli olmuştur. Üretken toplumun paylaşılan refahının yanında ortaya çıkan ayrı iş kolları, iş bölümü ve sınıf ayrılıkları yüzünden sadece doğaya değil, insan kendi kendine de yabancılaşmıştır. Geleneksel sorunlarla birlikte bir dizi yeni sosyal sorunlarla yüzleşmek zorunda kalmıştır. Toplumun aldığı bu karmaşık biçim insan ilişkilerinin bölünmesi demektir; özetle toplumsal zenginliğin artması, birçok bakımdan insan yoksulluğunun derinleşmesiyle sonuçlanmıştır. Başka bir ifade ile insanlar, sosyal refahın yanı başında sosyal eşitsizliği icat etmekle kalmayıp, birçok başarısız denemenin ardından, tarihte ilk defa günümüzde bunu kendi kendine devridaim yapabilecek hale getirmeye hiç olmadığı kadar yaklaştılar. Sosyal eşitsizliğin acı gerçekleri toplumdaki herkes için kötü olmaktadır (Fischer, 1993, s. 40, Bauman, 2015b, s. 16-20). Toplumun esenliği bundan doğrudan olumsuz etkilenmektedir. Toplumsal bütünleşme ve sosyal iyilik halini yükseltmek için evrensel deneyimlere odaklanmak gerekir. Bu nedenle sosyal politika uygulamasinda sosyal disiplin aktörlerinin hem bilim insanı hem de meslek elemanı olarak rolü, ifade edilen saptamalar neticesinde, sosyal patolojilerin/sosyal sorunların çözümüyle yakından ilişkilidir. Aynı şekilde "iş bölümünü toplumsal uyumun kaynağı kılan" ve "dayanışmayı toplumun varlık koşullarından biri gören" Durkheim'in görüşlerinin altını çizerek diyebiliriz ki, iş bölümüne dayalı organik toplumlarda sosyal politikanın, toplumun sağlıklı işleyişi yönünden bir etkileşim alanı ortaya çıkarabilmiş olduğudur. Bu anlamda Durkheim'in yazıları bilimsel saygınlığa iliş̧kin sağlam iddiası ile gelişmiş endüstriyel devletin gecikerek ortaya çıkışıyla yüzleşen sorunların ikna edici bir açıklamasının özgün bileşimini sunmuştur (Giddens, 2011, s. 187). Bunlar arasında iş bölümünün varlığı ve mesleki birliklerin gelişimi, Durkheim'in tezleriyle değerlendirildiğinde, sosyal politika yönüyle toplumsal dayanışmanın ve toplumsal bütünleşmenin öneminin artmasını da sağlayacaktır. Bu, günümüzde sosyal yardım anlamında mekanik dayanışmanın giderlerinin arttığı gerçeğini göz ardı edeceğimiz anlamına gelmemelidir. Toplumun refahı için kolektif giderleri, toplumsal bütünleşmeye katkı sağlarken, maliyetleri sürekli artıracaktır. Küresel eşitsizliklerin yoğunlaşması ile sosyal sorunların başka mecralara akması, bu maliyetleri çoğaltacaktır. Örneğin insan haklarına, dünya sisteminin bazı kesimlerinde diğerlerinkinden daha 
çok uyulmaktadır. Bunun doğru olduğundan kuşku yok. Ne var ki bu hakların daha az sorun oluşturur göründügüu ülkelerde bile hâlâ bütün bir iç bölge ya da nüfusun bütün bir tabakasında haklar düzenli bir biçimde ihlal ediliyor. Ve şu anki dünya sistemimizde nüfusun azalan değil, artan bir oranını oluşturan dünya göçmenleri o insan haklarından kötü bir ün yapacak ölçüde yoksunlar (Wallerstein, 2012, s. 115). Bu olumsuzluklar, diğer sosyal sorunlarla eklemleneceği için sosyal politikanın giderlerini de büyük boyutlarda etkileyecektir. Dolayısıyla sosyal huzursuzluklar karşısında, çağın koşullarıyla birlikte değerlendirilecek Durkheim'ci sosyal reformcu bir yaklaşım önemini korumaya devam edecektir. Bu nedenle mekanik dayanışmanın maliyeti, hayırseverlik odaklı geleneksel sosyal yardımlara yüklenirken, organik dayanışmanın maliyetinin sosyal politikaya yüklenmesini tarihsel-sosyal arka planıyla birlikte okumak gerekir.

Son tahlilde Durkheim, çağdaş sosyal teoride çok önemli izler bırakan ünlü bir sosyologdur. Bir sosyologların Durkheim'i vardır, bir sosyal antropologların Durkheim'i vardır, bir kriminologların Durkheim'i vardır, bir sosyal psikologların Durkheim'i vardır, bir eğitim sosyologlarının, bir ekolojistlerin, bir bilgi sosyolojisinin Durkheim'i vardır. Bir de yakın zamanların yapısalcılarının, öncüleri saydığı Durkheim vardır. Tıpkı Comte gibi, sosyal düzensizlikten (social disorder) endişe duyan ve nefret eden Durkheim'e göre, sosyal düzensizlikler modern dünyanın zorunlu bir parçası değildir ve sosyal reformlarla azaltılabilir. Durkheim, Kant'dan miras aldığı "ahlâki zorunluluk" düşüncesini iyice geliştirerek ve çağdaş toplumlara uygulayarak, kendinden sonra gelen ve özellikle toplumsal düzen konusuna ağırlık veren çok sayıda sosyal teorisyeni etkilemiştir (Kızılçelik, 1994, s. 212-213). Durkheim'in sosyal reform düşüncesinin 21. yüzyıla yansıması, sosyal politika ve meslek birliklerinin işlevinin yanında devlet müdahalesinin toplumsal esenliğe katkısını görmemiz adına yeni kapılar açmaktadır. Bu bağlamda sosyal teorinin, sosyal sorunlarla ilgili yapılacak çalışmalarda, sosyal politikaya yol gösterici olduğu bilinmektedir. Başka bir ifadeyle toplumsal esenlik ya da toplumun geliştirilmesi konusu her dönem tartışılmaya devam edilirken, sosyolojik bilginin ve sosyolojik düşünmenin sosyal politikayı değiştirmedeki rolü, işlenmeye devam edecektir. Kısaca sosyolojiyi de içinde barındıran sosyal teorinin gereksinim duyduğu şey, bir yandan insan yaşamının belirli toplumsal koşullar altında serpilememesini eleştirirken, öte yandan da haz, yaratıcılık ve özerklikle ilgili alternatif yaşam biçimlerine yönelik insani ihtiyaç ve arzuları savunabileceği çok-bakış aç11 yaklaşımlardır (Bottomore, 2000, s. 359, Coleman, 1997, s. 671696, Elliot, 2017, s. 428-429). Toplum ve birey var olduğu sürece, bu sosyal reformcu yaklaşımları içselleştirmiş bir bilimsel anlayış, iş bölümü, sosyal politika ve toplumsal dayanışmadan hareketle sosyal sorunların çözümünde yeni stratejiler belirlemek için düşünsel ve tarihsel bir zorunluluk olarak ağırlığını sürdürecektir.

\section{Kaynakça}

Bauman, Z. (2015a). Sosyolojik düşü̈mek (A. Yılmaz, Çev.). İstanbul: Ayrıntı Yayınları.

Bauman, Z. (2015b). Azınlı̆̆ın zenginliği hepimizin çıkarına mıdır? (H. Keser, Çev.). İstanbul: Ayrint1 Yayınları.

Bottomore, T.B. (2000). Toplumbilim (Ü. Oskay, Çev.). İstanbul: Der Yayınları.

Coleman, J. (1997). Sosyolojik çözümleme ve sosyal politika. R. Nisbet ve T. Bottomore (Ed), Sosyolojik çözümlemenin tarihi içinde (671-696). (M. Tuncay, A. Uğur, A. Kartal vd., Çev.), Ankara: Ayraç Yayınları.

Durkheim, E. (1985). Toplumbilimsel yöntemin kuralları (C. B. Akal, Çev.). İstanbul: BFS Yayınları.

Durkheim, E. (1992). İntihar (Ö. Ozankaya, Çev.). Ankara: İmge Yayınları.

Durkheim, E. (2014). Toplumsal iş bölümü. (Ö. Ozankaya, Çev.). İstanbul: Cem Yayınları. 
Elliot, A. (2017). Çağdaş sosyal teoriye giriş (S. T, Afşar, A. Ö, Boyacıŏ̆lu vd. Çev.). Ankara: Dipnot Yayınları.

Fischer, E. (1993). Sanatın gerekliliği (C. Çapan, Çev.). Ankara: Verso Yayınları.

Fromm, E. (1989). Yeni bir insan yeni bir toplum (N. Arat, Çev.). İstanbul: Say Yayınları.

Giddens, A. (2011). Sosyolojinin savunusu (İ. Kaya, Çev.). İstanbul: Say Yayınları.

Giddens, A. (2014). Kapitalizm ve modern sosyal teori, (Ü. Tatlıcan, Çev.). İstanbul: İletişim Yayınlar1.

Hobsbawm, E. (2012). Sermaye çă̆l, (M. S. Şener, Çev.). Ankara: Dost Yayınları.

Kızılçelik, S. (1994). Sosyoloji teorileri. Konya: Emre Yayınları.

Koray, M. ve Topçuoğlu, A. (1995). Sosyal politika. Bursa: Ezgi Yayınları.

Mazman, İ. (2008). Max Weber and Emile Durkheim: A comparative analysis on the theory of social order and the methodological approach to understanding society. Afyon Kocatepe Üniversitesi Sosyal Bilimler Enstitüsü Dergisi, 10 (1), 67-83.

Ritzer, G. ve Stepnisky, J. (2014). Sosyoloji kuramları (H. Hülür, Çev.). Ankara: De Ki Yayınları.

Şeker, A. (2015). 101 Soruda sosyal çalışma ve sosyal hizmetler. Ankara: Sabev Yayınları.

Talas, C. (1990). Toplumsal politika. Ankara: İmge Yayınları.

Wallerstein, I. (2012). Tarihsel kapitalizm ve kapitalist uygarlık(N. Alpay, Çev.). İstanbul: Metis Yayınları.

\section{ETİK ve BİLİMSEL İLKELER SORUMLULUK BEYANI}

$\mathrm{Bu}$ çalışmanın tüm hazırlanma süreçlerinde etik kurallara ve bilimsel atıf gösterme ilkelerine riayet edildiğini yazar(lar) beyan eder. Aksi bir durumun tespiti halinde Afyon Kocatepe Üniversitesi Sosyal Bilimler Dergisi'nin hiçbir sorumluluğu olmayıp, tüm sorumluluk makale yazarlarına aittir. 